\title{
A Simulation Analysis of Photovoltaic AC Module Integrated Converters in Parallel, under Controlled Edge Shading Conditions
}

\author{
Lynette O'Callaghan \\ Technological University Dublin, lynette.ocallaghan@tudublin.ie \\ Mick McKeever \\ Technological University Dublin, mick.mckeever@tudublin.ie \\ Brian Norton \\ Technological University Dublin, brian.norton@tudublin.ie
}

Follow this and additional works at: https://arrow.tudublin.ie/engmecdesignconf

Part of the Computer and Systems Architecture Commons, and the Energy Systems Commons

\section{Recommended Citation \\ O'Callaghan, L, McKeever, M., \& Norton, B. (2016). A Simulation Analysis of Photovoltaic AC Module Integrated Converters in Parallel, under Controlled Edge Shading Conditions. Environment and Electrical Engineering (EEEIC), 2012 11th International Conference, pp.699-705. doi:10.1109/EEEIC.2012.6221467}

This Conference Paper is brought to you for free and open access by the School of Mechanical and Design Engineering (old) at ARROW@TU Dublin. It has been accepted for inclusion in Conference Papers by an authorized administrator of ARROW@TU Dublin. For more information, please contact arrow.admin@tudublin.ie, aisling.coyne@tudublin.ie,gerard.connolly@tudublin.ie. Funder: TECHNOLOGICAL SECTOR RESEARCH (2007) STRAND III






\title{
A Simulation Analysis of Photovoltaic AC Module Integrated Converters in Parallel, under Controlled Edge Shading Conditions.
}

\author{
Lynette O'Callaghan, Michael McKeever, Brian Norton \\ Dublin Energy Lab (DEL) \\ Dublin Institute of Technology \\ Dublin, Ireland.
}

\begin{abstract}
A DC and AC power simulation comparison of: a Photovoltaic (PV) array with a modular, parallel, AC converter configuration; and a series, string configuration with a central AC converter, is presented. The systems are simulated using a comprehensive range of edge shading scenarios and irradiance conditions. Power control and transformation circuitry must be designed for shade and module mismatch tolerance to prevent over-proportional power to shade losses, as average losses from Building Integrated PV (BIPV) systems are approximately 20 to $\mathbf{2 5 \%}$, due to shade, mismatch, differences in orientation and inclination, and temperature effects. $59.4 \%$ of the simulations showed gains in AC power by using the parallel modular converter system, with a maximum gain of $10.74 \%$, when compared with the series configuration. Losses up to $6.61 \%$ can be experienced when most of the modules are experiencing edge shading of 200 or $400 \mathrm{~W} / \mathrm{m}^{2}$, as i) the converter efficiency is lower in this power range for the modular converter, and ii) this low efficiency conversion occurs $n$ times, where $n$ is the number of modules in the array. Significant power increases are experienced by the parallel modular system when there is a wide distribution of irradiance levels within the shading pattern.
\end{abstract}

Keywords-component; Photovoltaic, Converter, AC, Inverter, microinverter, MIC, AC MIC, configuration, model, simulation, BIPV, losses, gains.

\section{INTRODUCTION}

Building Integrated Photovoltaic (BIPV) products are designed to avail of existing space on a building that can be used to generate electricity for occupants and/or supply a grid, increase the users self-sustainability, decrease their reliance on fossil fuels and reduce the building's carbon footprint. To maximise the power generated, photovoltaic (PV) modules need to be mounted in a south facing orientation, in an area where shadows are not cast. When shade impacts a PV array, even by a small amount, the power losses have been measured and evaluated at $7.1 \%, 11 \%$ and $35 \%$ [1], [2], [3]. Shade manifests as cell mismatch and this loss, calculated through simulation, has been shown to be responsible for losses up to $10 \%$ of total generated power [4]. Utilising a correctly sized, high efficiency, central AC power converter (inverter) in a nonshaded system is the recommended practice. However, when modules are mounted vertically to replace windows, or as facades on a south facing wall, or when both eaves of a non-south facing roof are clad with photovoltaic tile, the power control and transformation circuitry must be designed for shade tolerance to prevent over-proportional power losses due to shade. Average losses from BIPV sytems are approximately 20 to $25 \%$, due to shade, mismatch, differences in orientation and inclination, and temperature effects [5].

The factors that influence the system maximum peak of available power are: irradiance, temperature, shading pattern, and array configuration [6]. The location and number of bypass diodes can also influence the maximum power point (MPP). Alternative wiring configurations have been shown experimentally to reduce mismatch losses by up to $4 \%$ for Total-Cross-Tied and Bridge-Link interconnection schemes [7]. Shade losses can be reduced in a Series-Parallel configuration, undergoing dynamic shading, where the number in of modules parallel is maximised and the number in series is minimised [8] [6]. Modular power converters offer module level Maximum Power Point Tracking (MPPT), which can result in a $25 \%$ energy enhancement [9], allowing each module to operate at its MPP. However series connected modular converters also experience module mismatch losses, due to current mismatch. DC or AC parallel wired modular converter systems feeding a constant bus do not suffer from module mismatch losses [10], as the configuration removes current and voltage mismatch between modules. This paper investigates the $\mathrm{AC}$ power output of an AC Module Integrated Converter (MIC) configuration wired in parallel, when shade introduces significant mismatch in the system. This configuration is shown in fig 1(a). The modular power converter and controller performs a high gain voltage transformation of power to supply single phase AC power from each module, and designs can be found in [11] and [12].

A simulation of DC electrical characteristics of PV modules connected in a series under various partial shade conditions [13] is extended in this paper to include a sample central inverter efficiency curve, enabling $\mathrm{AC}$ power predictions, as in fig 1(b). 


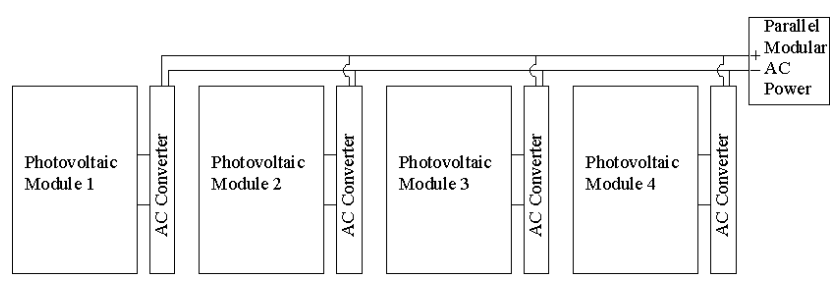

(a) Parallel bus configuration of PV modules and modular AC converters

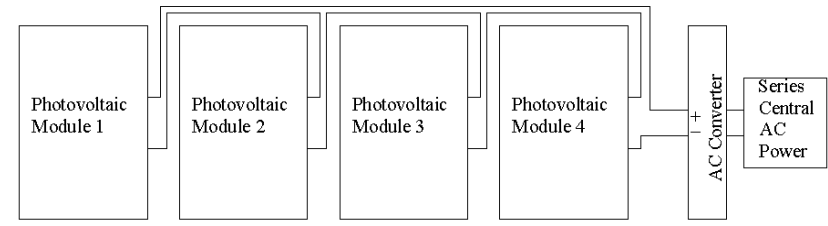

(b) Series configuration of modules with a central AC converter Fig. 1. Configurations.

The aim of the paper is to provide a rigorous analysis through simulation of the behaviour of the AC MIC parallel configuration, in order to quantify its gains and losses in $\mathrm{AC}$ power, in relation to a series string configuration with central AC converter. It is assumed that each system is being operated at the maximum available DC MPP. Each configuration's output power is a strong function of the efficiency curve of the AC converter. Converter efficiency curves have been derived and extrapolated from experimental data. The relative increase or decrease in power output of each configuration is quantified, as a function of shade intensity and area. The simulations provide a library of power-voltage curves for each system configuration, for a comprehensive range of i) edge shading patterns and ii) shade intensity. The $\%$ mismatch, the AC power differential, and the $\%$ gain or loss in $\mathrm{AC}$ power are presented for each shade scenario and PV system configuration.

\section{MODELING}

\section{A. PV Model}

A model of a PV module is used to predict module power. Temperature variations are not considered in this analysis, and each module is assumed to be operated at $25^{\circ} \mathrm{C}$. The model requirements are: i) to generate a power voltage curve with sufficient accuracy, ii) to be able to incorporate multiple bypass diodes and iii) to vary input environmental factors with ease. The Matlab/Simulink software has been chosen as the electrical components and environmental inputs can be modeled simultaneously. The performance of the model is compared with published experimental data from a state of the art PV module. Three bypass diodes, installed at uneven intervals of 24, 12 and 24 series connected cells, are modeled in each module. This emulates the state of the art module design to be used in further experimental analysis at DIT.

The simplified equivalent circuit of an ideal solar cell consists of a current source in parallel with a diode. In order to achieve a more accurate model, more complexity can be introduced to the model by adding in turn 1) temperature dependence on the photo current $I_{p h}, 2$ ) temperature dependence on the diode saturation current $I_{D}, 3$ ) series resistance, $R_{S}$, which represents relatively small losses due to connection point resistance, 4) parallel resistance, $R_{P}$, which represents leakage current and 5) a second diode with an independent diode saturation current [14]. All parameters are included, except for the second diode, as it did not lead to improvements in accuracy. The current I can be written using the single diode model of a photovoltaic cell as in (1).

$$
I=I_{p h}-I_{0}\left[\exp \left\{\frac{V+I R_{S}}{n V_{T}}\right\}-1\right]-\frac{\left(V+I R_{S}\right)}{R_{P}}
$$

Where $I_{p h}$ is the photo generated current; $I_{0}$ is the diode reverse saturation current; $\mathrm{V}$ is the cell voltage; $\mathrm{n}$ is the diodeideality factor, $R_{S}$ and $R_{P}$ are the series and the parallel resistances; $V_{T}$ is the thermal voltage.

$$
V_{T}=\frac{k T}{e}
$$

Where $\mathrm{k}$ is the Boltzmann's constant, $\mathrm{T}$ is the temperature in ${ }^{\circ} \mathrm{K}$, and e is the electron charge.

$$
I_{p h}=G\left(C_{P T} T+C_{P G}\right)
$$

The constant $\mathrm{C}_{\mathrm{PT}}$ is used to represent temperature dependence. The relation of the number of suns $\mathrm{G}$ and the photocurrent is expressed by the constant $\mathrm{C}_{\mathrm{PG}}$.

$$
I_{D}=C_{D} T^{3} \exp \left\{-\frac{e V_{g a p}}{k T}\right\}
$$

$\mathrm{V}_{\text {gap }}$ is the Band-Gap Voltage, a material constant. $\mathrm{C}_{\mathrm{D}}$ is one of the model parameters that have to be tuned to realize an accurate simulation. The parameters were chosen to limit error at the MPP to $\pm 2.5 \%$ of the MPP power.

The model has been created to simulate a state of the art module, made with a thin mono-crystalline silicon wafer surrounded by ultra-thin amorphous silicon layers. Unlike monocrystalline silicon cells, the slope of the curves in the area of voltage higher than $\mathrm{V}_{\mathrm{MPP}}$ changes for different irradiance conditions. The slope of the curves is mainly influenced by the series resistance, where a lower resistance causes a higher slope in the V-I curve. For this reason, the models have been modified by making the series resistance depending on the irradiance level.

$$
R_{\text {Smod }}=\frac{R_{S}}{G}
$$

The comparison of simulated and measured data, as seen in Fig. 2 and 3, show significant power differences near the open circuit voltage of the IV curve, above $35 \mathrm{~V}$, however each maximum power point occurs at voltages below $35 \mathrm{~V}$, as seen in table 1.

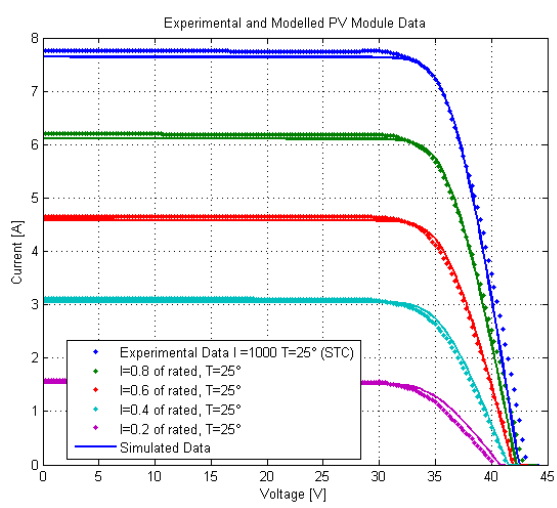

Fig. 2. Experimental and modeled PV IV curves. 


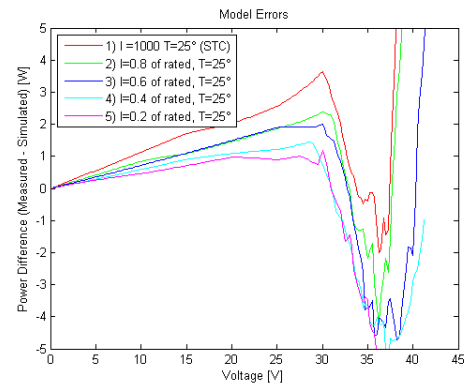

Fig. 3. PV model errors

TABLE 1 ERROR ANALYSIS DATA

\begin{tabular}{|l|l|l|l|l|}
\hline Series & MPP $(\mathbf{W})$ & $\mathbf{U}_{\text {MPP }}(\mathbf{V})$ & $\begin{array}{l}\text { Power Difference } \\
(\mathbf{W})\end{array}$ & $\begin{array}{l}\text { \%Error } \\
\text { at MPP }\end{array}$ \\
\hline 1$)$ & 253.89 & 34.5 & -0.484 & $-0.19 \%$ \\
\hline 2$)$ & 200.71 & 34.5 & -1.26 & -0.63 \\
\hline 3$)$ & 148.69 & 33.75 & -1.50 & -1.01 \\
\hline 4$)$ & 96.67 & 33.50 & -2.35 & -2.43 \\
\hline 5$)$ & 47.13 & 32.25 & -1.11 & -2.36 \\
\hline
\end{tabular}

The percentage power difference error at the maximum power points in series 1 and 2 is less than 1\%; and in series 3, 4 \& 5 is between 1 and $2.5 \%$. The model over-estimates the available power at a maximum of $2.5 \%$ at the MPPs, deeming the model within acceptable levels of accuracy.

\section{B. Array Model}

All modules are assumed to be mounted at the same orientation and angle. It is assumed that all modules have identical electrical characteristics, and that all mismatch is due to shade induced mismatch. Differences in performance calculated are due to shading mismatch losses and power transformation losses, as wiring losses are not considered.

\section{Efficiency Models}

It is assumed that each PV configuration is being operated at the maximum available DC MPP. The central inverter is a transformerless design, and the efficiency curve for the model is derived from experimental data from [15]. The peak efficiency of the curve is $97.65 \%$. The modular AC converter uses a high frequency transformer in its design, and an efficiency-power curve was derived from normalised experimental efficiency curves of a push pull AC converter [16]. The overall maximum efficiency of this design did not compare with micro-inverters currently on the market. The curve was shifted to a maximum peak power to match the commercial AC converter of $94.8 \%$ [17]. The aim is to preserve the relations within the efficiency curve, assumed to be due to its design.

The source curves presented in the paper are normalised and for this model it is assumed that the inverter is sized 1:1, rated power of the inverter : STC power rating of the generator. In terms of selecting efficiency curves it should be noted that a great range of distributions and peak efficiency values are possible, as the inverter's efficiency is highly dependent on the dc voltage and the inverter output power [15]. This dependence, along with efficiency as a function of power, is not standard data found in manufacturers' datasheets. For these reasons the data curves are chosen as acceptable samples of high efficiency modern PV converters. The data was translated into polynomials of the order of 10 and 20 for central- and modular- converters respectively, with mean absolute differences in efficiency values, measured minus modelled, of 0.028 and 0.001 . The two curves are presented in Fig. 4.

\section{SIMULATION INPUTS AND OUTPUTS}

\section{A. Simulation Inputs - Shade Area and Intensity}

\section{a) Shade Area Scenarios}

There are four modules in each PV system examined, totaling $1 \mathrm{~kW}$ of STC power. The four shade scenarios in Fig. 5 are examined for each configuration. The module sections in white are experiencing STC conditions of $1000 \mathrm{~W} / \mathrm{m}^{2}$ and $25^{\circ} \mathrm{C}$. Each module is wired with three bypass diodes, shown as three sections in each module. The top sections only will experience shade in this analysis, enabling comprehensive edge shading analysis.

\section{b) Shade Intensity Variations}

Within each of the shade scenarios in Fig. 5, the intensity of the irradiance of the shaded section is initially set to 800 $\mathrm{W} / \mathrm{m}^{2}$, and reduced to 600,400 , and $200 \mathrm{~W} / \mathrm{m}^{2}$ respectively. All combinations are evaluated for each shade scenario. Within a module, the notation used to indicate what irradiance is present is: $\mathrm{x} / \mathrm{y} / \mathrm{z}$, where $\mathrm{x}$ is the irradiance of the top bypass section, $\mathrm{y}$ the middle bypass section, and $\mathrm{z}$ the bottom bypass section. Finally $1000 \mathrm{~W} / \mathrm{m}^{2}$ is represented as $1,800 \mathrm{~W} / \mathrm{m}^{2}$ as 0.8 etc. The irradiance levels are read from the charts in Figs. $6 \& 7$.
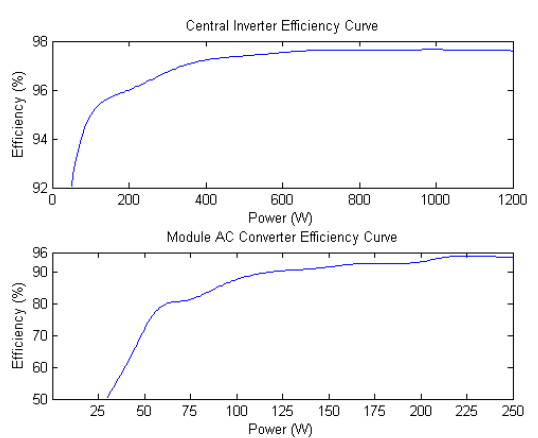

Fig. 4 Efficiency curves

Fig. 5 Shade Scenarios

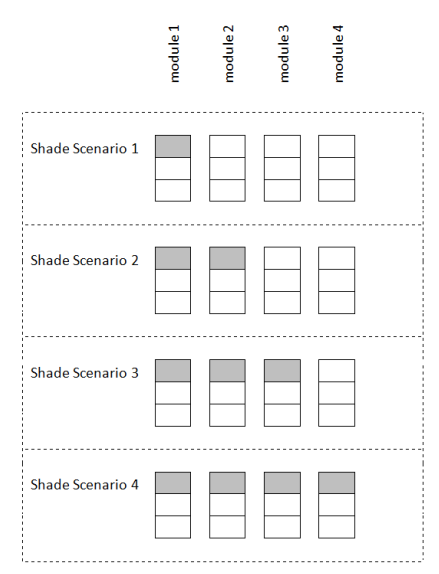




\section{B. Simulaton Outputs}

1) Maximum DC power available from each configuration before conversion to AC.

2) Maximum $\mathrm{AC}$ power available from each configuration.

3) $\mathrm{AC}$ Power difference, indicating the $\mathrm{AC}$ power gained or lost by using the AC MIC parallel configuration compared with the series central configuration, for each shade scenario.

4) The location of $U_{M P P} D C(V)$ for each environmental condition.

5) The $\%$ mismatch losses in the series configuration is calculated using:

$=\frac{\mathrm{P}_{\mathrm{DC} \text { modular parallel power }}-\mathrm{P}_{\mathrm{DC} \text { series central power }}}{\mathrm{P}_{\mathrm{DC} \text { modular parallel power }}} \times 100$,

as the DC modular parallel power is the maximum power that could be extracted if all modules were operated at their MPPs. It is a measure of current mismatch only, as there are no parallel connections, which would incur voltage mismatch losses. It does not measure cell mismatch between cells within a module.

6) The $\%$ gain/loss of the parallel modular configuration is calculated using:

$$
=\frac{P_{A C \text { Modular Parallel }-P_{A C \text { Series Central }}}}{P_{\text {AC Series Central }}} \times 100
$$

\section{RESULTS}

An individual PV module's power-voltage curves, undergoing edge shading for all intensity variations, are shown in Fig. 6. Table 3 outlines $\mathrm{U}_{\mathrm{MPP}}, \mathrm{P}_{\mathrm{DC}}$ and $\mathrm{P}_{\mathrm{AC}}$, incorporating the AC MIC efficiency transformation. In Fig. 6 , curve $b$, the module can generate $216 \mathrm{~W}$ of power with 1 bypass diode section experiencing irradiance of $800 \mathrm{~W} / \mathrm{m}^{2}$, by drawing the power at a voltage of $35.46 \mathrm{~V}$. The option to bypass the shaded section is present at a lower power peak of $144.68 \mathrm{~W}$, if the impedance is matched using a voltage of $19.64 \mathrm{~V}$. In this scenario, it is not advantageous to avail of the alternative power peak, as the module is contributing more power when sacrificing the extra power of the unshaded sections to the shaded section. The alternative is to bypass the shaded section, in favour of recouping the full power available from the two bypass sections. A similar scenario applies to curve c). For case d), if the shaded section is not bypassed, the power generated would be $114.69 \mathrm{~W}$. By drawing the power at

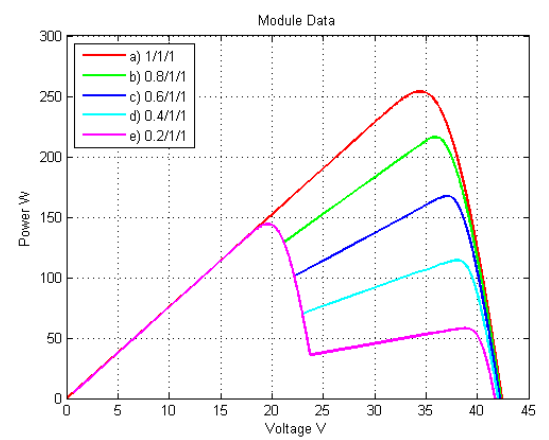

Fig. 6 Module PV Curves
TABLE 3. MODULE DC AND AC POWER DATA

\begin{tabular}{|c|c|c|c|}
\hline Chart Identifier & $\mathbf{U}_{\text {MPP }}(\mathbf{V})$ & $\mathbf{P}_{\text {DC MPP }}(\mathbf{W})$ & $\mathbf{P}_{\text {AC MPP }}(\mathbf{W})$ \\
\hline a) & 34.46 & 254.31 & 240.22 \\
\hline b) & 35.95 & 216.58 & 205.13 \\
\hline c) & 37.10 & 167.76 & 155.16 \\
\hline d) & 19.64 & 144.68 & 131.74 \\
\hline e) & 19.64 & 144.68 & 131.74 \\
\hline
\end{tabular}

$19.64 \mathrm{~V}$, and hence bypassing the shaded section, the power available would be $144.68 \mathrm{~W}$. The power dissipation occurring from the low irradiance experienced by the shaded section becomes too great a cost for the module between the irradiances of 510 and $520 \mathrm{~W} / \mathrm{m}^{2}$, and more power can be recouped from the module by completely bypassing it.

The charts in Fig. 7 show the DC power-voltage curves of the series wired PV system, for each shade scenario and intensity. Table 4 details the simulated output results for each configuration. Each system configuration has four modules, totaling $1 \mathrm{~kW}$. In Fig. 7 , shade scenario 1 curve a), it can be seen that more power can be generated by bypassing the section of module experiencing lower irradiance. If the voltage is set to $123.01 \mathrm{~V}$ then the current drawn by the system is, $7.38 \mathrm{~A}$, and the power is $907.60 \mathrm{~W}$. This allows the other three modules and the two other section of the partially shaded module, all not experiencing shade, to generate at their full current potential. The other options is to apply a voltage of 146.64V and draw a current of $6.1 \mathrm{~A}$ from the system. All modules would have to operate at the lower current, as they are wired in series, thus generating a total of $892.55 \mathrm{~W}$. As the irradiance on the shaded section becomes lower, in case b), c), and d), the situation stays the same and the section is bypassed.

$59.4 \%$ of the simulations showed gains in power production using the parallel modular converter system. The average $\%$ mismatch in the series central system is $5.4 \%$, at a maximum of $13.33 \%$. There is no case where the DC power generated by the series central system is greater than the modular parallel system. The maximum gain is experienced in shade scenario 3 case e. (3e) The parallel system would generate $755.67 \mathrm{~W}$ as opposed to 682.40 for the series case. This is an increase of $73.27 \mathrm{~W}$, which is a $10.74 \%$ increase on the series configuration. Case $2 \mathrm{~b}, 4 \mathrm{e}$ and $3 \mathrm{~b}$ experience increases of $7.91 \%, 7.02 \%$, and $4.96 \%$. These four cases are experiencing combinations of 1000,800 , and $600 \mathrm{~W} / \mathrm{m}^{2}$ only.

Other significant increases in power occur in cases i) $41 \& \mathrm{~m}$, ii) $3 \mathrm{f} \& \mathrm{~g}$, iii) $2 \mathrm{c} \& \mathrm{~d}$, and iv) $4 \mathrm{n}, \mathrm{o} \& \mathrm{p}$, offering increases of $8.62 \%, 7.31 \%, 4.90 \%$, and $6.2 \%$ respectively. These power increases are made even though there is a wide distribution of irradiances, all including an 800, a 600 and either a 400 or 200 $\mathrm{W} / \mathrm{m} 2$ irradiance levels. Cases $4 \mathrm{~m}$ shows that in a varied edge shading scenario, where all modules in the system are effected, a small amount of severe shading can be tolerated and the power increases can be preserved, in this case $8.62 \%$. 

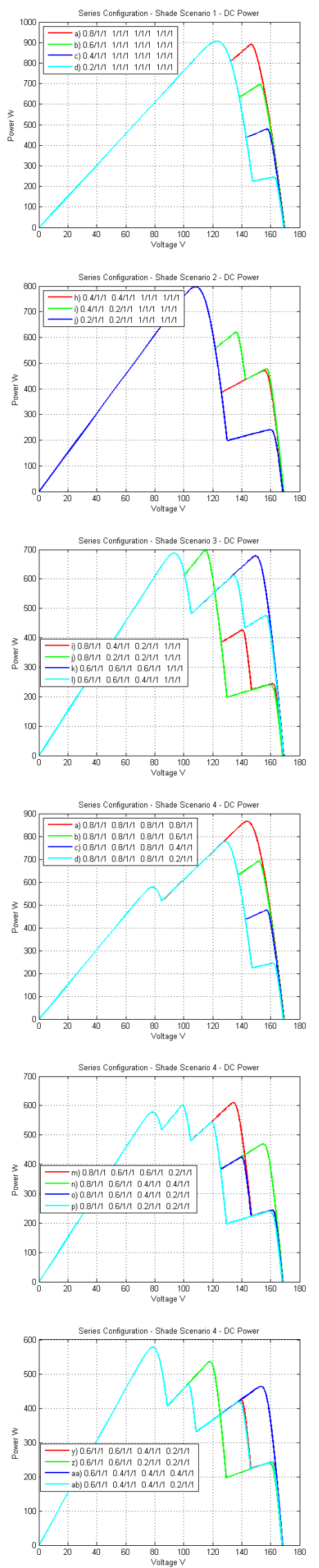

Fig 7 Series Configuration DC Power-Voltage curves
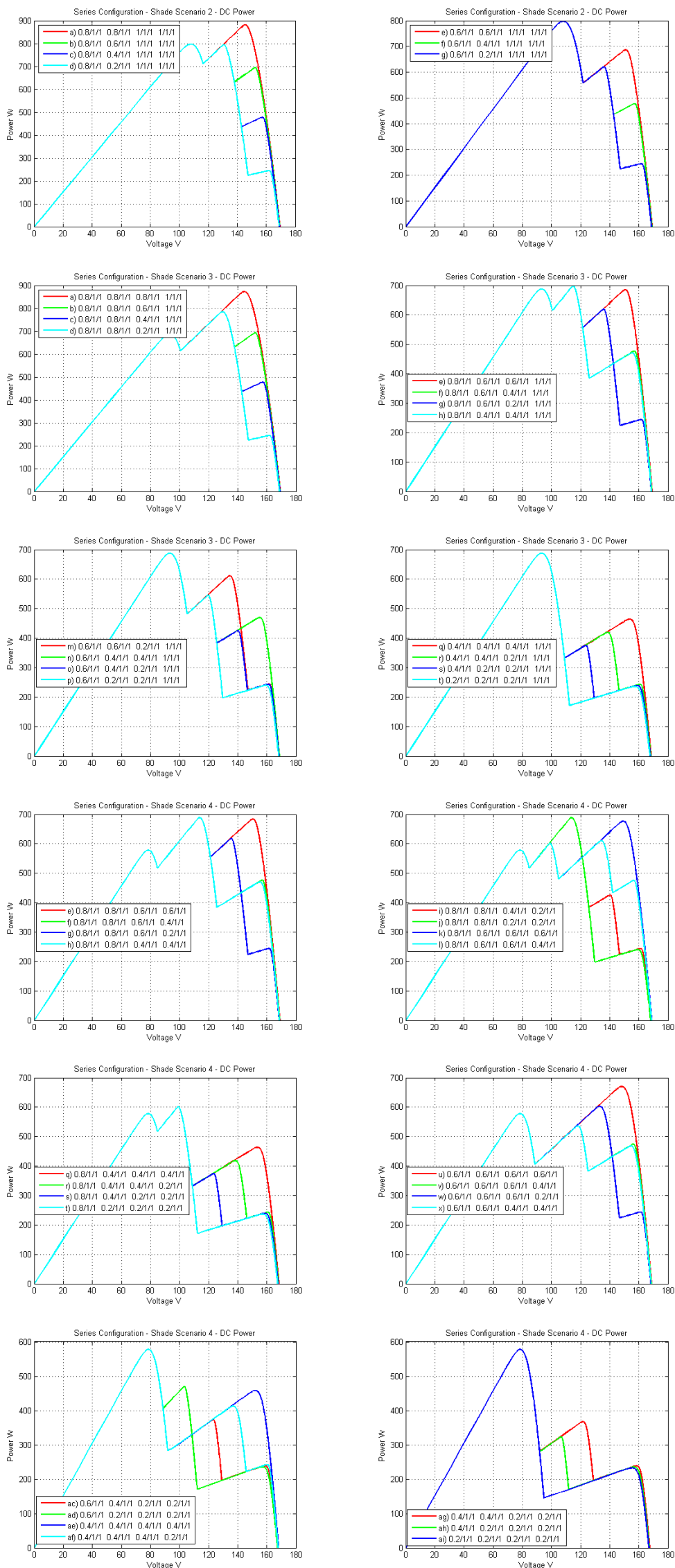


\begin{tabular}{|c|c|c|c|c|c|c|c|c|c|}
\hline $\begin{array}{c}\text { Shade } \\
\text { Area } \\
\text { Scenario } \\
\text { (Fig. 5) } \\
\end{array}$ & $\begin{array}{c}\text { Irradiance } \\
\text { Pattern } \\
\text { (Fig. 7) }\end{array}$ & $\begin{array}{c}\mathbf{U}_{\text {MPP }}(\mathbf{V}) \\
\text { Series-Cen }\end{array}$ & $\begin{array}{l}\mathbf{P}_{\text {MPP DC }}(\mathbf{W}) \\
\text { Series-Cen }\end{array}$ & $\begin{array}{c}P_{\text {MPP AC }}(\mathbf{W}) \\
\text { Series-Cen }\end{array}$ & $\begin{array}{c}\text { P }_{\text {MPP DC }}(W) \\
\text { Parallel-Mod }\end{array}$ & $\begin{array}{c}P_{\text {MPP AC }}(\mathbf{W}) \\
\text { Parallel-Mod }\end{array}$ & $\begin{array}{c}\text { Mismatch } \\
\% \\
\text { Series-Cen }\end{array}$ & $\begin{array}{c}\text { AC Power } \\
\text { Difference } \\
\text { (W) }\end{array}$ & $\begin{array}{c}\text { Gain/Loss } \\
\%\end{array}$ \\
\hline \multirow{4}{*}{1} & a) & 123.01 & 907.60 & 886.16 & 979.51 & 925.80 & $7.34 \%$ & 39.64 & $4.47 \%$ \\
\hline & b) & 123.01 & 907.60 & 886.16 & 930.69 & 875.82 & $2.48 \%$ & -10.33 & $-1.17 \%$ \\
\hline & c) & 123.01 & 907.60 & 886.16 & 907.61 & 852.40 & $0.00 \%$ & -33.75 & $-3.81 \%$ \\
\hline & d) & 123.01 & 907.60 & 886.16 & 907.61 & 852.40 & $0.00 \%$ & -33.75 & $-3.81 \%$ \\
\hline \multirow[t]{10}{*}{2} & a) & 145.54 & 882.66 & 861.75 & 941.78 & 890.71 & $6.28 \%$ & 28.95 & $3.36 \%$ \\
\hline & b) & 108.19 & 797.97 & 779.1 & 892.96 & 840.73 & $10.64 \%$ & 61.63 & $7.91 \%$ \\
\hline & c) & 108.19 & 797.97 & 779.1 & 869.88 & 817.32 & $8.27 \%$ & 38.21 & $4.90 \%$ \\
\hline & d) & 108.19 & 797.97 & 779.1 & 869.88 & 817.32 & $8.27 \%$ & 38.21 & $4.90 \%$ \\
\hline & e) & 108.19 & 797.97 & 779.1 & 844.15 & 790.76 & $5.47 \%$ & 11.65 & $1.50 \%$ \\
\hline & f) & 108.19 & 797.97 & 779.1 & 821.06 & 767.34 & $2.81 \%$ & -11.76 & $-1.51 \%$ \\
\hline & g) & 108.19 & 797.97 & 779.1 & 821.06 & 767.34 & $2.81 \%$ & -11.76 & $-1.51 \%$ \\
\hline & h) & 108.19 & 797.97 & 779.1 & 797.98 & 743.92 & $0.00 \%$ & -35.18 & $-4.52 \%$ \\
\hline & i) & 108.19 & 797.97 & 779.1 & 797.98 & 743.92 & $0.00 \%$ & -35.18 & $-4.52 \%$ \\
\hline & j) & 108.19 & 797.97 & 779.1 & 797.98 & 743.92 & $0.00 \%$ & -35.18 & $-4.52 \%$ \\
\hline \multirow[t]{20}{*}{3} & a) & 144.62 & 874.08 & 853.36 & 904.05 & 855.62 & $3.32 \%$ & 2.26 & $0.26 \%$ \\
\hline & b) & 129.72 & 786.13 & 767.56 & 855.23 & 805.65 & $8.08 \%$ & 38.08 & $4.96 \%$ \\
\hline & c) & 129.72 & 786.13 & 767.56 & 832.15 & 782.23 & $5.53 \%$ & 14.66 & $1.91 \%$ \\
\hline & d) & 129.72 & 786.13 & 767.56 & 832.15 & 782.23 & $5.53 \%$ & 14.66 & $1.91 \%$ \\
\hline & e) & 114.96 & 698.95 & 682.40 & 806.42 & 755.67 & $13.33 \%$ & 73.27 & $10.74 \%$ \\
\hline & f) & 114.96 & 698.95 & 682.40 & 783.33 & 732.25 & $10.77 \%$ & 49.85 & $7.31 \%$ \\
\hline & g) & 114.96 & 698.95 & 682.40 & 783.33 & 732.25 & $10.77 \%$ & 49.85 & $7.31 \%$ \\
\hline & h) & 114.96 & 698.95 & 682.40 & 760.25 & 708.84 & $8.06 \%$ & 26.43 & $3.87 \%$ \\
\hline & i) & 114.96 & 698.95 & 682.40 & 760.25 & 708.84 & $8.06 \%$ & 26.43 & $3.87 \%$ \\
\hline & j) & 114.96 & 698.95 & 682.40 & 760.25 & 708.84 & $8.06 \%$ & 26.43 & $3.87 \%$ \\
\hline & k) & 93.38 & 688.34 & 672.01 & 757.60 & 705.70 & $9.14 \%$ & 33.69 & $5.01 \%$ \\
\hline & 1) & 93.38 & 688.34 & 672.01 & 734.52 & 682.28 & $6.29 \%$ & 10.27 & $1.53 \%$ \\
\hline & m) & 93.38 & 688.34 & 672.01 & 734.52 & 682.28 & $6.29 \%$ & 10.27 & $1.53 \%$ \\
\hline & n) & 93.38 & 688.34 & 672.01 & 711.43 & 658.86 & $3.25 \%$ & -13.15 & $-1.96 \%$ \\
\hline & o) & 93.38 & 688.34 & 672.01 & 734.52 & 658.86 & $6.29 \%$ & -13.15 & $-1.96 \%$ \\
\hline & p) & 93.38 & 688.34 & 672.01 & 711.43 & 658.86 & $3.25 \%$ & -13.15 & $-1.96 \%$ \\
\hline & q) & 93.38 & 688.34 & 672.01 & 688.35 & 635.44 & $0.00 \%$ & -36.57 & $-5.44 \%$ \\
\hline & r) & 93.38 & 688.34 & 672.01 & 688.35 & 635.44 & $0.00 \%$ & -36.57 & $-5.44 \%$ \\
\hline & s) & 93.38 & 688.34 & 672.01 & 688.35 & 635.44 & $0.00 \%$ & -36.57 & $-5.44 \%$ \\
\hline & t) & 93.38 & 688.34 & 672.01 & 688.35 & 635.44 & $0.00 \%$ & -36.57 & $-5.44 \%$ \\
\hline \multirow[t]{35}{*}{4} & a) & 143.81 & 866.32 & 845.78 & 866.32 & 820.53 & $0.00 \%$ & -25.25 & $-2.99 \%$ \\
\hline & b) & 128.85 & 777.83 & 759.47 & 817.50 & 770.56 & $4.85 \%$ & 11.09 & $1.46 \%$ \\
\hline & c) & 128.85 & 777.83 & 759.47 & 794.42 & 747.14 & $2.09 \%$ & -12.33 & $-1.62 \%$ \\
\hline & d) & 128.85 & 777.83 & 759.47 & 794.42 & 747.14 & $2.09 \%$ & -12.33 & $-1.62 \%$ \\
\hline & e) & 113.94 & 689.68 & 673.32 & 768.69 & 720.58 & $10.28 \%$ & 47.26 & $7.02 \%$ \\
\hline & f) & 113.94 & 689.68 & 673.32 & 745.60 & 697.16 & $7.50 \%$ & 23.84 & $3.54 \%$ \\
\hline & g) & 113.94 & 689.68 & 673.32 & 745.60 & 697.16 & $7.50 \%$ & 23.84 & $3.54 \%$ \\
\hline & h) & 113.94 & 689.68 & 673.32 & 722.52 & 673.75 & $4.55 \%$ & 0.43 & $0.06 \%$ \\
\hline & i) & 113.94 & 689.68 & 673.32 & 722.52 & 673.75 & $4.55 \%$ & 0.43 & $0.06 \%$ \\
\hline & j) & 113.94 & 689.68 & 673.32 & 722.52 & 673.75 & $4.55 \%$ & 0.43 & $0.06 \%$ \\
\hline & k) & 149.38 & 677.61 & 661.49 & 719.87 & 670.61 & $5.87 \%$ & 9.12 & $1.38 \%$ \\
\hline & 1) & 134.34 & 610.78 & 595.81 & 696.79 & 647.19 & $12.34 \%$ & 51.38 & $8.62 \%$ \\
\hline & m) & 134.34 & 610.78 & 595.81 & 696.79 & 647.19 & $12.34 \%$ & 51.38 & $8.62 \%$ \\
\hline & n) & 99.11 & 602.21 & 587.38 & 673.70 & 623.77 & $10.61 \%$ & 36.39 & $6.20 \%$ \\
\hline & o) & 99.11 & 602.21 & 587.38 & 673.70 & 623.77 & $10.61 \%$ & 36.39 & $6.20 \%$ \\
\hline & p) & 99.11 & 602.21 & 587.38 & 673.70 & 623.77 & $10.61 \%$ & 36.39 & $6.20 \%$ \\
\hline & q) & 99.11 & 602.21 & 587.38 & 650.62 & 600.36 & $7.44 \%$ & 12.97 & $2.21 \%$ \\
\hline & r) & 99.11 & 602.21 & 587.38 & 650.62 & 600.36 & $7.44 \%$ & 12.97 & $2.21 \%$ \\
\hline & s) & 99.11 & 602.21 & 587.38 & 650.62 & 600.36 & $7.44 \%$ & 12.97 & $2.21 \%$ \\
\hline & t) & 99.11 & 602.21 & 587.38 & 650.62 & 600.36 & $7.44 \%$ & 12.97 & $2.21 \%$ \\
\hline & u) & 148.41 & 671.06 & 655.06 & 671.06 & 620.63 & $0.00 \%$ & -34.42 & $-5.25 \%$ \\
\hline & v) & 133.25 & 603.80 & 588.94 & 647.97 & 597.22 & $6.82 \%$ & 8.28 & $1.41 \%$ \\
\hline & w) & 133.25 & 603.80 & 588.94 & 647.97 & 597.22 & $6.82 \%$ & 8.28 & $1.41 \%$ \\
\hline & $\mathrm{x})$ & 78.57 & 578.72 & 564.28 & 624.89 & 573.80 & $7.39 \%$ & 9.52 & $1.69 \%$ \\
\hline & y) & 78.57 & 578.72 & 564.28 & 624.89 & 573.80 & $7.39 \%$ & 9.52 & $1.69 \%$ \\
\hline & z) & 78.57 & 578.72 & 564.28 & 624.89 & 573.80 & $7.39 \%$ & 9.52 & $1.69 \%$ \\
\hline & aa) & 78.57 & 578.72 & 564.28 & 601.80 & 550.38 & $3.84 \%$ & -13.90 & $-2.46 \%$ \\
\hline & ab) & 78.57 & 578.72 & 564.28 & 601.80 & 550.38 & $3.84 \%$ & -13.90 & $-2.46 \%$ \\
\hline & ac) & 78.57 & 578.72 & 564.28 & 601.80 & 550.38 & $3.84 \%$ & -13.90 & $-2.46 \%$ \\
\hline & ad) & 78.57 & 578.72 & 564.28 & 601.80 & 550.38 & $3.84 \%$ & -13.90 & $-2.46 \%$ \\
\hline & ae) & 78.57 & 578.72 & 564.28 & 578.72 & 526.96 & $0.00 \%$ & -37.31 & $-6.61 \%$ \\
\hline & af) & 78.57 & 578.72 & 564.28 & 578.72 & 526.96 & $0.00 \%$ & -37.31 & $-6.61 \%$ \\
\hline & ag) & 78.57 & 578.72 & 564.28 & 578.72 & 526.96 & $0.00 \%$ & -37.31 & $-6.61 \%$ \\
\hline & ah) & 78.57 & 578.72 & 564.28 & 578.72 & 526.96 & $0.00 \%$ & -37.31 & $-6.61 \%$ \\
\hline & ai) & 78.57 & 578.72 & 564.28 & 578.72 & 526.96 & $0.00 \%$ & -37.31 & $-6.61 \%$ \\
\hline
\end{tabular}


A disadvantage of the system can be explained by looking at cases i) $2 \mathrm{~h}, \mathrm{i}, \mathrm{j}$, ii) $3 \mathrm{q}, \mathrm{r}, \mathrm{s}, \mathrm{t}$, iii) $4 \mathrm{ae}$,af,ag,ah,ai. The losses are $4.52 \%, 5.44 \%$ and $6.61 \%$ respectively. All of these cases show combinations incorporating 200 and $400 \mathrm{~W} / \mathrm{m}^{2}$ only, sometimes combined with unshaded modules. When the irradiance is $400 \mathrm{~W} / \mathrm{m}^{2}$ or lower, it is bypassed in both configurations. The limit is approximately $500 \mathrm{~W} / \mathrm{m}^{2}$, as described in the discussion of Fig. 6. The extra losses in the parallel modular system stem from the increased number of efficiency conversions due to the modular converter design, and the lower conversion efficiency at that power range. In Fig 6. case $\mathrm{d}$ and e, the overall power is low, $144.68 \mathrm{~W}$, and the conversion efficiency is occuring at a lower value of $91 \%$. For the cases of greatest loss: 4ae,af,ag,ah,ai; this low conversion efficiency is occurring 4 times, giving an overall reduced system performance.

Case $3 \mathrm{k}$ and $4 \mathrm{u}$ give very interesting results. In $3 \mathrm{k}$, when 3 out of 4 modules are experiencing edge shading of $600 \mathrm{~W} / \mathrm{m}^{2}$, $\mathrm{AC}$ power increases of $33.69 \mathrm{~W}$ are available, a $5.01 \%$ increase in power using the parallel modular system. The series central system has two peaks to choose from, one at $688 \mathrm{~W}(93.38 \mathrm{~V})$ and the other at $678.89 \mathrm{~W}(149.66 \mathrm{~V})$. All of the $600 \mathrm{~W} / \mathrm{m}^{2}$ sections are bypassed, to draw the higher current being supplied by the unshaded sections, and the mismatch is $9.14 \%$. The parallel modular system does not bypass the shaded sections of the shaded modules, and the unshaded module can deliver all of it power, leading to overall power increases. However in case $4 \mathrm{u}$, where the four modules are experiencing edge shading of $600 \mathrm{~W} / \mathrm{m}^{2}$, the losses are $5.25 \%$. The series central MPP occurs at $677.61 \mathrm{~W}$ by drawing a current of $4.5 \mathrm{~A}$ indicating that the shaded sections are not bypassed at this MPP. With both configurations, more power is produced by not bypassing. The available DC power is the same for each configuration, with no mismatch in the series central system. The loss is primarily due to the number of conversions in the modular system. The multiple efficiency transformations however, do not have a negative effect in case $3 \mathrm{k}$, because of the high level of mismatch in the series central system.

\section{CONCLUSIONS}

An AC power simulation comparison of a PV array with AC MIC parallel configuration; and a series, string configuration with a central AC converter, is presented. The systems are simulated using a comprehensive range of edge shading scenarios and irradiance conditions. $59.4 \%$ of the simulations showed gains in power production using the parallel modular converter system, where the maximum gain is a $10.74 \%$ increase in AC Power produced. The system works best when there is light shade, above $600 \mathrm{~W} / \mathrm{m}^{2}$, and when there is a high distribution of shade intensities, which leads to a high level of module mismatch, as in case $3 \mathrm{e}$. However a small proportion of severe shade, $200 \mathrm{~W} / \mathrm{m}^{2}$, can also be tolerated within these conditions, with $8.65 \%$ increases in power (case $4 \mathrm{~m}$ ). The system shows significant losses when the majority of the edge shading is 400 or $200 \mathrm{~W} / \mathrm{m}^{2}$, as the multiple converter efficiency transformation losses are too costly at low powers. One of the primary disadvantages of the AC MIC system is the inability to achieve power increases when uniform edge shading occurs over all of the modules, as the series central system works more efficiently when shade is uniform in both area and irradiance, as in case $4 \mathrm{a}$ and $4 \mathrm{u}$. However if only one of the modules are unshaded, then the power increases can be significant, as seen in case $3 \mathrm{k}$, due to the high level of module mismatch. The AC MIC system is recommended for systems expecting highly distributed levels of shade irradiance and shade area patterns.

\section{REFERENCES}

[1] T. Sugiura, T. Yamada, H. Nakamura, M. Umeya, K. Sakuta, K. Kurokawa, 2003. Measurements, analyses and evaluation of residential PV systems by Japanese monitoring program, Solar Energy Materials and Solar Cells, 75 (), pp. 767-779/

[2] Baltus, C.W.A, Eikelboom, J.A., van Zolingen, R.J.C., 1997. Analytical monitoring of losses in PV systems. In: 14th European Photovoltaic Solar Energy Conference, July, Barcelona, Spain, pp. 1547-1550.

[3] Becker, H., Kiefer, K., Hoffman, V.U., Rindelhardt, U., Heilscher, G., 1997. Five years of operational experience in the German 1000-roofs-PV programme results of monitoring and system inspection. In: 14th European Photovoltaic Solar Energy Conference, July, Spain, pp. 1677-1680.

[4] Chouder, A, 2009. Analysis model of mismatch losses in PV systems. Journal of Solar Energy Engineering 131(May) 024504.

[5] E. Román, R. Alonso, P. Ibanez, S. Elorduizapatarietxe, D. Goitia, 2006. Intelligent PV module for grid-connected PV systems, IEEE Trans on Industrial Electronics, 53 (2006), pp. 1066-1073.

[6] Patel, H.; Agarwal, V, 2008. "MATLAB-Based Modeling to Study the Effects of Partial Shading on PV Array Characteristics," Energy Conversion, IEEE Transactions on, vol.23, no.1, pp.302-310, March.

[7] D. Picault, B. Raison, S. Bacha, J. de la Casa, J. Aguilera, 2010. Forecasting photovoltaic array power production subject to mismatch losses, Solar Energy, Volume 84, Issue 7, July, Pages 1301-1309.

[8] C.R. Sánchez Reinoso, D.H. Milone, R.H. Buitrago, 2010. Efficiency study of different photovoltaic plant connection schemes under dynamic shading, International Journal of Hydrogen Energy, Volume 35, Issue 11, June, Pages 5838-5843.

[9] Enslin, J.H.R.; Wolf, M.S.; Snyman, D.B.; Swiegers, W., 1997, "Integrated photovoltaic maximum power point tracking converter," Industrial Electronics, IEEE Transactions on, vol.44, no.6, pp.769-773, Dec.

[10] W. Xiao, N. Ozog, W.G. Dunford, 2007. Topology study of photovoltaic interface for maximum power point tracking, IEEE Trans. Ind Electron., vol 54, no. 3, pp 1696-1704, June.

[11] Woo-Young Choi, Jih-Sheng (Jason) Lai, 2010. High-efficiency gridconnected photovoltaic module integrated converter system with high-speed communication interfaces for small-scale distribution power generation, Solar Energy, Volume 84, Issue 4, April, Pages 636-649

[12] Shimizu, T.; Wada, K.; Nakamura, N., 2006."Flyback-Type Single-Phase Utility Interactive Inverter With Power Pulsation Decoupling on the DC Input for an AC Photovoltaic Module System," Power Electronics, IEEE Transactions on, vol.21, no.5, pp.1264-1272, Sept.

[13] Mäki, A., Valkealahti, S. and Leppäaho, J, 2011. Operation of seriesconnected silicon-based photovoltaic modules under partial shading conditions. Progress in Photovoltaics: Research and Applications.

[14] G. R. Walker. 2001.Evaluating mppt converter topologies using a matlab pv model. Journal of Electrical \& Electronics Engineering, Australia, Vol.21(No.1):49_56,

[15] Valentini, M.; Raducu, A.; Sera, D.; Teodorescu, R, 2008. "PV inverter test setup for European efficiency, static and dynamic MPPT efficiency evaluation," Optimization of Electrical and Electronic Equipment, 2008. OPTIM 2008. 11th International Conference, 22-24 May.

[16] Herrmann, U.; Langer, H.G.; van der Broeck, H.,1993. "Low cost DC to AC converter for photovoltaic power conversion in residential applications," Power Electronics Specialists Conference, 1993. PESC '93 Record., 24th Annual IEEE, vol., no., pp.588-594, 20-24 Jun

[17] Enecsys Micro Inverters, (2012) 'datasheets Smi-S240W-60 [online] http://www.enecsys.com/products/datasheets.php [ 02/02/12]. 